\title{
The Relationship between the Decision-Making Process and the Emotional Intelligence in E-Society: A Time Series Analysis of Choosing a University Product
}

\author{
Ion-Dănuț LIXANDRU \\ The Bucharest University of Economic Studies, Romania \\ danut.lixandru@gmail.com
}

In a world where information is one of the most valuable resources, which both organizations and individuals want to make the most of, choices are becoming increasingly difficult to anticipate, even if a multitude of tools are available to us. The evolution of emotional intelligence, based on the opportunities created by e-society, makes the need for analysis from a psycho-social perspective become an element of major importance for organizations. The differences between the generations of consumers, easily detectable from the outside (regarding the way of choosing the products), have, however, a difficult process to explain. This article aims to find a correlation between the changes brought about by the information society at the level of the emotional intelligence of individuals regarding the aspect of the decision on the choice of a product, in this case, a university product.

Keywords: Emotional intelligence, E-society, University marketing, Time series analysis

DOI: $10.24818 /$ issn14531305/24.1.2020.08

1 Introduction

In the new circumstances of today's society, the need for continuous adaptation, as well as the prediction of consumers' wishes, become a sine-qua-non element in any type of organization. Changes in contemporary society bring with them different needs or desires than those of individuals of past generations. Observationally, one can distinguish the idea that the current society, based on the use of information, also called the information society, fulfills in a much easier way the function of exchange between organizations and consumers (B2C) or even between organizations (B2B). The diversity of the economic processes carried out in the new economy, therefore, leads to a change of the economic, social, but also political environment, and puts as a basis of good functioning the organization's relationship with the client.

Alnfrah and Mouselli [1] have content that is truly meaningful, claiming that we live in the era of "globalized knowledge that became the basis of the production process" and more than ever, this process consists not of physical elements but of the individual and social capital, which represents the most valuable resource of organizations. Thus, from the moment when the focus was on the possession of the private monopoly, on the waste of material goods (the capitalist and industrial society), it was reached a period when the intangible (the information) possesses the full attention and and many characteristic changes of the new society have a great degree of differences.

With this development, the triggering factor, namely the Internet, has become the main environment in which organizations carry out their activities, and at the same time, it has changed the way of buying decisions.

The role of marketing science in today's society becomes essential, in order to connect the organization with its consumers. Thus, marketing in the e-society puts at its center the individualized customer, with his needs and desires, trying to fulfill in this way as many of them as possible. For the permanent adaptation to the demands of the environment, both in the case of marketing and of the esociety, an anticipatory approach to the evolution of the climate of its own habitat is required. The social-economic dynamism achieves a bridge between these two distinct domains that lead to a new form of the economy. This evolution, therefore, leads to a change and at the psychological level of 
individuals, who, with the information at hand, develops a new type of decision-making process, based on numerous influences, especially of emotional nature.

\section{Emotional intelligence in decision- making}

To better understand the connection between the decision-making process and emotional intelligence, it is necessary to know a definition of emotional intelligence, which, according to Serrat [2] is the possibility or ability of an individual to raise awareness, to appreciate and to manage one's own emotions. or those of others, individuals with a high degree of empathy. This capacity has a wide applicability in all the activity of the individual, but especially when he is in front of a decision that can influence his life. In making the decision, a major importance is the awareness of the result and the way in which it affects both himself and others, and the moment when the decision maker considers this aspect, it is about emotional intelligence [3]. An extremely interesting approach on emotional intelligence has Mayer et. all [4], which assigns a set of seven principles to it, as follows:

- Emotional intelligence is a mental ability;

- Emotional intelligence is better measured as a skill;

- Intelligent problem solving does not necessarily correspond to intelligent behavior;

- A specific test is needed to measure it;

- A well-defined test can prove to be a skill;

- Emotional intelligence is a "broad intelligence";

- Emotional intelligence is intelligence based on the processing of hot information.

At the observational level, we can deduce that all these principles are based on a well-defined psychological structure, born or acquired throughout the life of the individual, but which requires a great deal of information. Taking this into consideration, and assigning validity to the claim that the current society is an information-based one, one can derive the idea that most individuals in the society possess this ability, called emotional intelligence, and depending on how well it is developed, the choices include it.

Although most articles tend to attribute emotional intelligence to leaders, those who are able to make important decisions for their organizations or those in which they work, extrapolating and adapting contextually, we can refer to Newman's model [5] and to the level of individual when he have to take the decision to purchase the product. As can be seen in Figure 1, which includes a series of competencies in the success of a leader, skills that are becoming more relevant and applicable to the individuals of the contemporary society, it can be distinguished that these attributes according to a leader, lead to a total belonging to the social environment and also a strong connection with the need for information, adaptation to this environment, characteristics that are extremely developed for most of today's individuals.

Even if, on a comparative level, the two structures (the individual - the consumer and the individual - the leader), have a relatively different importance of the decision, in the sense that the impact of their decision may have opposite consequences, the intensity of the emotion may have the same or even greater rhythm in the decision. the case of a decision of the consumer-individual. Hypothetically and contextually, if we think about a future student who will choose a bachelor's degree, the intensity of emotion during the election increases if it takes into account both the impact on its future and the opinion of other individuals who serve as external influence on it. Also, a human resources manager, when promoting a new employee, to the detriment of one with considerable seniority in the department, the intensity of the emotion increases when it takes into account the motivation of the older employee, but, in comparison with the consumer individual, he is not includes himself in the decision, perhaps only his relationship with subordinates. 


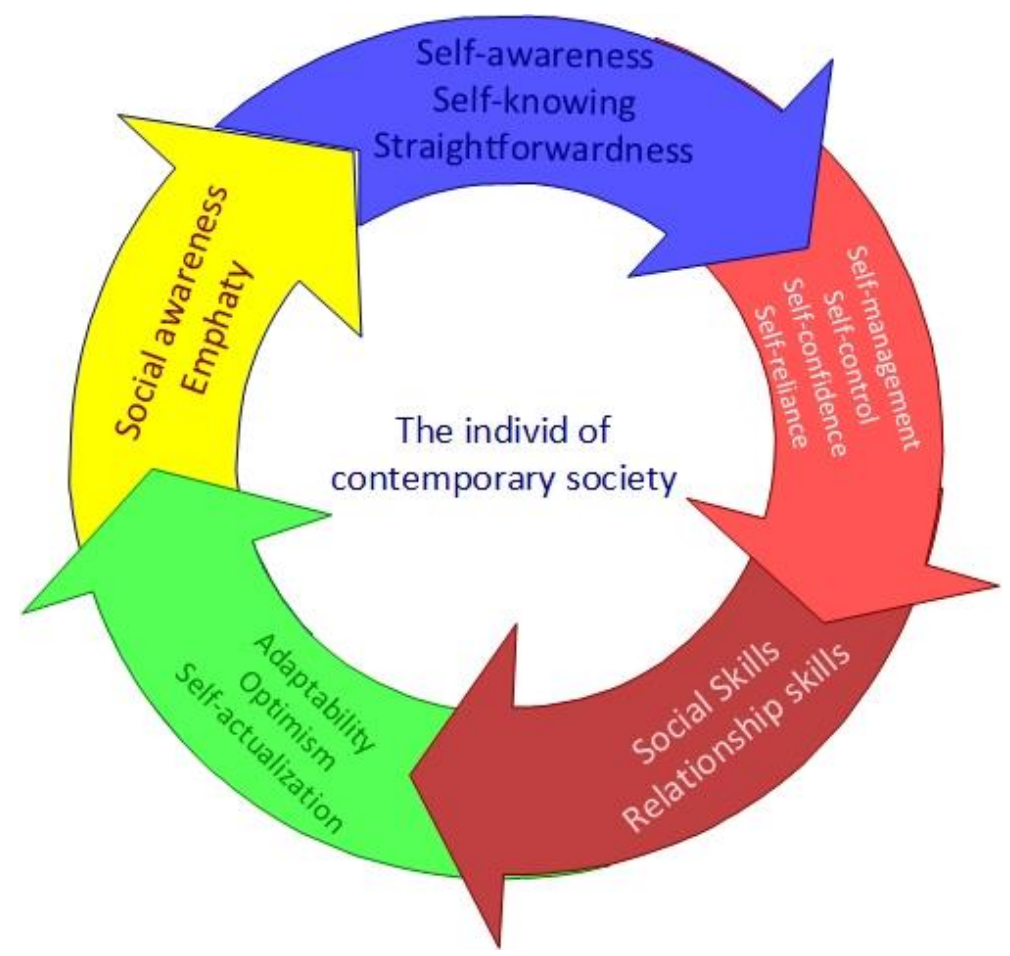

Fig. 1. Adaptation of a leader's emotional intelligence model [5]

What the previous model (Figure 1) is trying to show, is the idea of modeling the knowledge of the individual, taking into account the factor called society, and as Stehr and Adolf [6] say, our knowledge is a "social construction" nowadays. , and this perspective is relatively recent. In other words, the influence that society has on the knowledge or information that the individual processes, changes the human genetic structure, which is transferable from generation to generation.

To summarize the aforementioned aspects, it can be said that information is the key factor in contemporary society, and the individual changes influenced by the social factor, especially at the psychological level, the mode of action on a factor.

An extremely important source in informing the individual, which has become a very powerful influence on his psychic nowadays, is the internet. The current society, based on the exchange of information, passes easily, easily under the absolute power of the Internet.

Turning our attention to what the Internet wants to achieve, several interconnected nodes, which share the same information, one can infer the idea that the skills, mentioned in Newman's model, can be owned by the most individuals in this network.

To get an idea of what this network means, it is very relevant what happens to e-commerce. If at the beginning of e-commerce (1990s), the period was one of search, experimentation, in the 2000s the strategy was one of reevaluation, and between 2002-2008 ecommerce had a growth of more than 25\% [7] in our days, one of the most used networks that makes the growth possible has managed to bring $33 \%$ of the world's population into the same space, as we can see in Figure 2. 


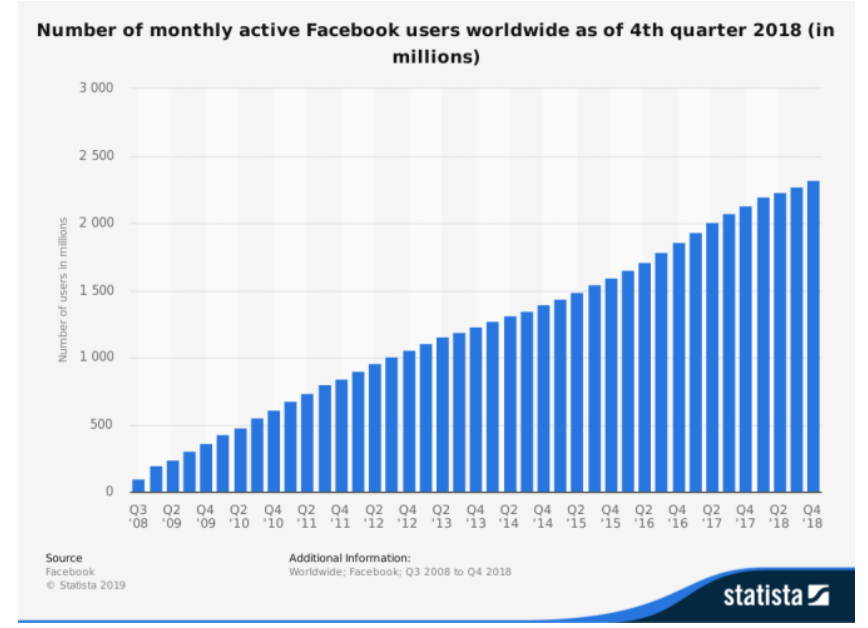

Fig. 2. Number of Facebook users [8]

Information and communication technology has undergone a developmental process over the last few years, due to progress in areas such as electronics, computer science and communications, reaching a stage where it can cope with the process called globalization [9].

In order for this link, created between peoples from this network, to be possible and the information to be transmitted, there must be a connection mode through which the information flow can flow. The Internet is the most relevant way to connect individuals in order to share information between network members.

If, overall, the purpose of the Internet is to create connections, looking at the perspective of today's students, the Internet is a way of life that has a level of global attraction, it is a tool for promoting and distributing knowledge [10]. Starting from the above statement, it is logical to argue that this is a tool with a high degree of influence on the activity of the students, and plays an important role in making a decision, becoming the main information medium.

The more organizations manage to keep up with new technologies and the information is transmitted more efficiently, the greater the likelihood of attracting and / or retaining consumers, and their decisions about choosing a product / service become more anticipatory and easier to satisfy. Although the most powerful organizations have moved to the online environment, to be as close to their customers as possible, an effective marketing strategy also includes different techniques or actions in the traditional environment, but one that should be considered in a large measure, the changes produced by the new company at the consumer level.

\section{Changes Produced by the E-Society}

The vast character of the e-society, gives the possibility to transpose and apply it in different environments, such as the political, administrative, social, legal, economic, cultural but also individual [11]. It is worth noting, in this case, at the individual level, in a behavioral sense, the changes brought about by the e-society, which [12] bring new expectations and even regarding the working environment, "the esteem and the possibility of leaving the footprint "are becoming important elements for the employees.

The development of this society therefore covers a multitude of areas, which provide various means of stabilization, modernization or even growth / evolution. A simple overview (over a long period) of an area in which the information society puts its mark, can confirm the gradual transition to a higher level.

If most theories are based on explanations of the changes produced by specific activities, the overall process, at the individual (psychological) level, is less targeted. As Stoica says, the individual receives a number of advantages by having access to information much easier and the possibility to "interact socially" [11], but the current tendency shows 
an increase in the lack of physical interaction between individuals. Thus, the decisions they make become not an impulse of desire, but an external influence on the part of the society created in the virtual environment, an imposition of conformist norms and therefore it acts on the individual as an expected response stimulus, similar to the training principle.

What the current society intends is the continuous development, with the help of the Internet, a single network that has managed to bring the majority of the individuals of the society in the same environment and which gives the advantage of fast information that can be processed and adapted without interruption, each node (individual) bringing a plus network value.

Lucas, et al., [13] give a broad meaning of what the users of these networks are looking for, referring to what they offer, namely social interaction, free facilities, control and / or refresh of knowledge, all created by the desire for knowledge and involvement of the members. However, these desires create groups with different behaviors and, on the same principle, differences between the generations of users according to age.

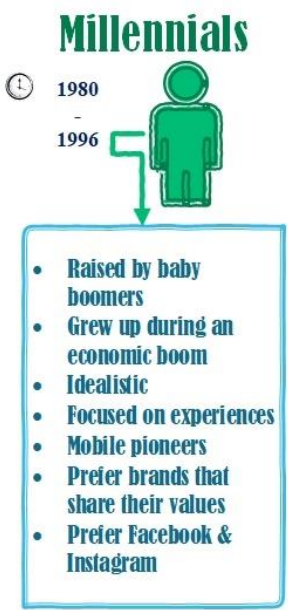

The tendency and influence of the new society, exercised over the individual, can be seen from the differences and characteristics of the generations. For example, if we turn our attention to the last 3 generations, namely generation x (born 1965-1980), generation y / millennials (born 1981-1995) and generation $\mathrm{z}$ (born after 1995), the discrepancy is quite a great. If in the case of generation $\mathrm{x}$, the information was difficult to find and the technological process existed only at the industrial level, millennials are the so-called "pioneers" generation of digitalization, and as many authors argue in the article written by Nicholas and Wright [14], they they have grown in the age of digitalization and are connected through social media, and their mode of information is based on the widespread use of technology. The generation of millennial substitutes undergoes a total behavioral change. Compared to both generations mentioned above, they were born in a world without technology. The differences between millennials and centennials can be seen in the picture below (Figure 3):

Fig. 3. Differences between generation y and generation z [15]

In order to understand the differences produced by the effect of the information society, I ordered the research of their decision differences, in the context of the influence of the information society, starting from the premises developed by the science of attracting consumers, namely marketing, in an area where the decision is made in the long term and looks at the future of these generations, education.

Zait [16] states that educational marketing aims at issuing, amplifying and accommodating study programs in relation to market requirements, as well as applying 
communication and motivation techniques, more specifically consumer awareness and adaptation to new conditions created by society. Therefore the implication of the new e-society in this field, gives the possibility to find a way of development, taking into account the changes produced by it.

In the continuation of the article we will observe whether the differences imposed by the e-society reach the purchasing decision rule by analyzing a series of time.

\section{Research Methodology}

The basis for defining the purpose of the research is the determination by forecast of the number of students admitted to the Faculty of Marketing from ASE Bucharest, considering as a factor of influence on the decision to choose the university program, the e-society and the changes offered to this field of study on consumer behavior.

The aim of the research is to determine the most appropriate model of forecasting and to know the extent to which the e-society has, over a period of time, been a factor of growing influence over the decision to acquire a university program.

At the level of objectives, research aims at:

- Determining the extent to which changes made by the e-society have been considering when enrolling in college and reporting differences between generations;

- Determining the evolution of the number of students;

- Identifying the best predictive method, related to the studied subject;

- Measuring the degree of association of the number of students admitted to the Faculty of Marketing with those successful at the Baccalaureate exam for a period of 10 years.

Research assumptions:

- H1. Generation z (centennials) took a great considering of technological changes when purchasing the university product (license program);

- H2. Most respondents belong to the generation with the lowest number of admitted in the analyzed time series;
- H3. The number of students admitted to the Marketing Faculty is directly proportional to the number of students admitted to the Baccalaureate exam;

- H4. The tendency of the admitted is an ascending one,

- H5. The best way to predict is to use the linear model;

- H6. Generation differences determine the volatility of the number of admitted students.

I have collected the secondary data from the Faculty of Marketing (ASE Bucharest), namely the number of students admitted here, starting with the 2009-2010 promotion so far, was organized in order to carry out the research as objectively as possible. Another source of data was a short survey that was started using the Google Forms platform, containing a questionnaire with 3 questions, which I have shared with the official faculty group Facebook network, with time coordinates 17-24 February 2019. All observation units were able to complete the questionnaire, the sampling method being an exhaustive one.

I analyzed the date using SPSS and Microsoft Excel.

The following mathematical equations which I used to determine the prediction model and the residual error size as well as the average absolute deviation:

The linear model: $\mathrm{Y}_{\mathrm{i}}=\mathrm{a}+\mathrm{b}^{*} \mathrm{X}_{\mathrm{i}}$

The polynomial model: $Y_{i}=a+b \times X_{i}+c * X_{i}^{2}$

The exponential model: $\mathrm{Yi}=\mathrm{a} \times \mathrm{b}^{\mathrm{Xi}}$,

Where: $\mathrm{Yi}$ - the value of the predicted variable in the " $i$ " period;

$\mathrm{Xi}$ - reference period "i";

$\mathrm{a}, \mathrm{b}-$ model parameters

Residual Error: $\mathrm{SS}_{\mathrm{E}}=\sum_{i=1}^{n}\left(y_{i}-\hat{y}_{i}\right)^{2}=$

$$
\sum_{i=1}^{n} e_{i}^{2}
$$

Average absolute deviation: $\mathrm{AMA}=$

$$
\frac{\sum_{i=1}^{n}\left|y_{i}-\hat{y}_{i}\right|}{n}
$$

\section{Research Results}

After the questionnaire was administered, a total of 54 respondents responded as follows: 


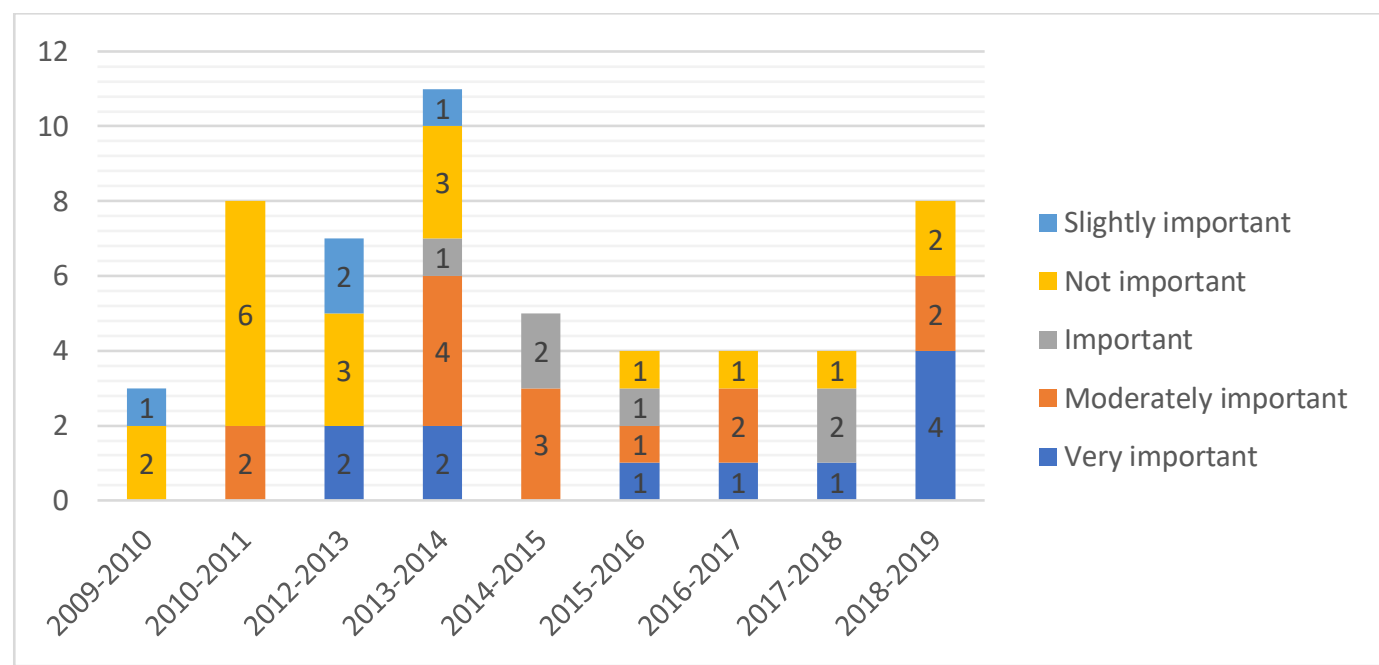

Fig. 4. Distribution of responses

The hypothesis from which this study has been started, states that generation $\mathrm{Z}$ takes very much into consideration technological change when deciding to choose a university product, as can be seen (Figure 4) from 2015 onwards, 2016, when they were admitted, $40 \%$ of them say they have taken the technological dynamics to a very high degree, followed by those with no less than $25 \%$, then those with very little $20 \%$ and $15 \%$ to a large extent, by consequently $\mathrm{H} 1$ can be accepted. As can be seen in Table 1, contrary to the $\mathrm{H} 2$, 2010, 2013 and 2014 have the largest number of representatives, and the majority $(37.5 \%)$ said that the evolution of technology has influenced very little in the choice of the faculty, therefore, we can assert the null hypothesis.

In a logical order, the number of students should increase relative to the number of students who have obtained the Baccalaureate [17] but as can be seen in Figure 5, the fluctuations are slightly different, so the two values have the same proportional direction.
Table 1. Number of students admitted to Faculty of Marketing

\begin{tabular}{|c|c|}
\hline Year & $\begin{array}{c}\text { Admitted to } \\
\text { college }\end{array}$ \\
\hline 2009 & 455 \\
\hline 2010 & 353 \\
\hline 2011 & 411 \\
\hline 2012 & 414 \\
\hline 2013 & 374 \\
\hline 2014 & 371 \\
\hline 2015 & 430 \\
\hline 2016 & 410 \\
\hline 2017 & 441 \\
\hline 2018 & 435 \\
\hline
\end{tabular}

Analyzing the link between the two variables, the Pearson correlation coefficient with the value of 0.084 shows a positive and directly proportional relationship, but with a very weak statistically significant relationship (pvalue $=0.817$ from Table 2 ) . 
Table 2. Pearson Correlation

\begin{tabular}{|cc|c|c|}
\hline & & College & Baccalaureate \\
\hline \multirow{3}{*}{ College } & Pearson & 1 & .084 \\
& Correlation & 1 & .817 \\
& Sig. (2-tailed) & & 10 \\
\hline \multirow{3}{*}{ Baccalaureate } & Pearson & 10 & 1 \\
& Correlation & .084 & \\
& Sig. (2-tailed) & .817 & 10 \\
& $\mathrm{~N}$ & 10 & 10 \\
\hline
\end{tabular}

\section{Correlation}

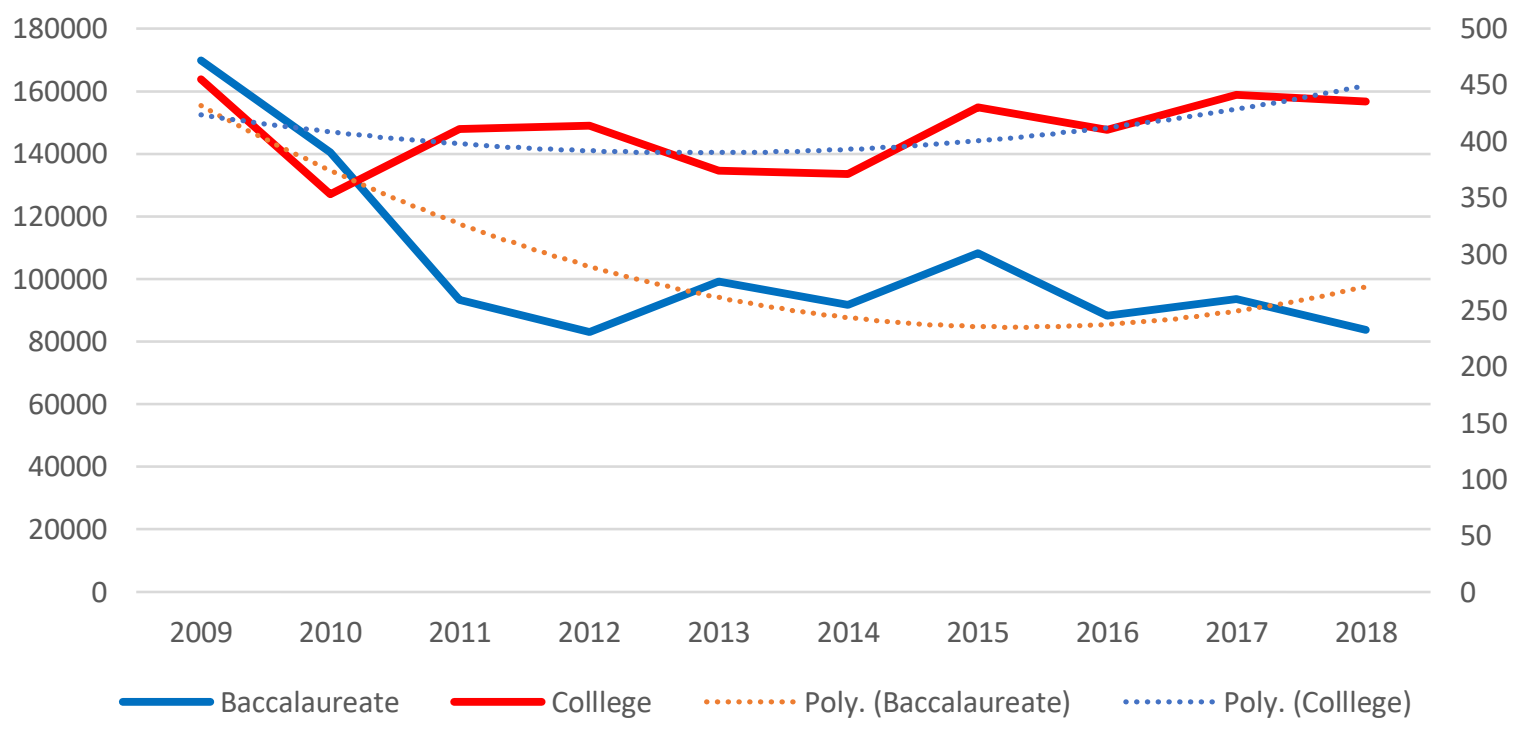

Fig. 5. Graphical correlation of the number of students admitted to the successful baccalaureate

In order to calculate the trend of the chronological analysis, i determined, using the above-mentioned mathematical equations, the equation applied for 3 different prediction models, the linear model, the polynomial model and the exponential model. As can be seen in the following graph, the differences between these models express an uncertainty about determining an ascending or descending trend, the linear and exponential models showing an increase and the polynomial showing volatility. The determination coefficient $\mathrm{R}^{2}$ calculated for each model shows very low values for the linear model (0.068) and exponential (0.0752), so we can see (in Figure 6) that both equations have a low degree of applicability of the regression equation and thus can be accepted the hypothesis according to which the trend is ascending, accepting the polynomial model equation. 


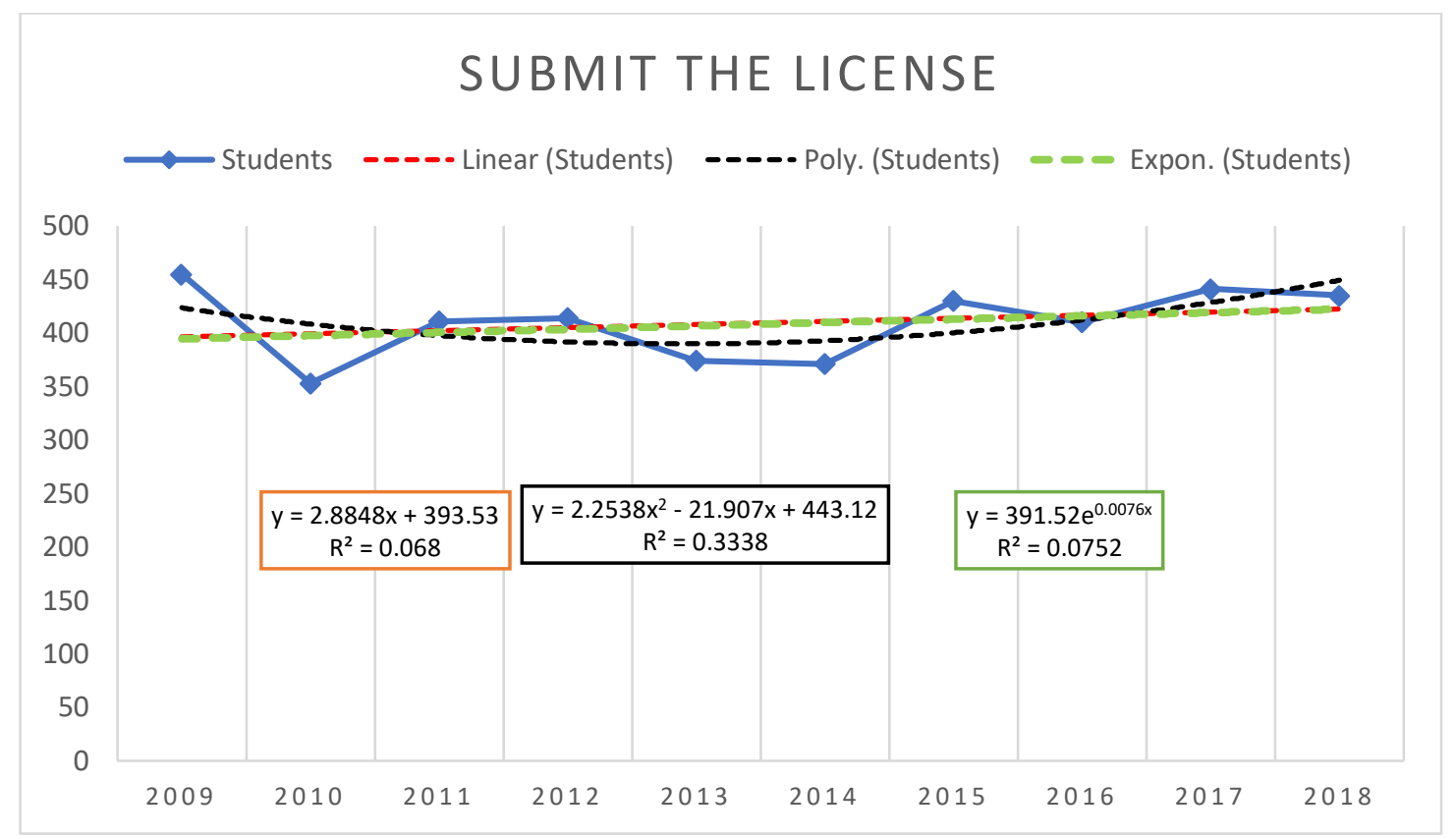

Fig. 6. The trend of the registration number at the Faculty of Marketing

To determine with greater precision which of the models is best for estimating the number of students for the following years, the size of the residual error and the absolute mean deviation were calculated for all three models, as can be seen in Figure 7.

\begin{tabular}{|c|c|c|c|c|c|c|c|}
\hline Year & $Y_{i}$ & Y & Linear Model & Polynomial Model & Exponential Mc & lodel & \\
\hline $2009-2010$ & 455 & 0 & 394 & 443 & 392 & & \\
\hline 2010-2011 & 353 & 1 & 396 & 423 & 395 & & \\
\hline 2011-2012 & 411 & 2 & 399 & 408 & 398 & & \\
\hline $2012-2013$ & 414 & 3 & 402 & 398 & 401 & & \\
\hline 2013-2014 & 374 & 4 & 405 & 392 & 404 & & \\
\hline $2014-2015$ & 371 & 5 & 408 & 390 & 407 & & \\
\hline $2015-2016$ & 430 & 6 & 411 & 393 & 410 & & \\
\hline 2016-2017 & 410 & 7 & 414 & 400 & 413 & & \\
\hline $2017-2018$ & 441 & 8 & 417 & 412 & 416 & & \\
\hline $2018-2019$ & 435 & 9 & 419 & 429 & 419 & & \\
\hline $2019-2020$ & & 10 & 422 & 449 & 422 & & \\
\hline $2020-2021$ & & 11 & 425 & 475 & 426 & & \\
\hline \multirow{3}{*}{ 2021-2022 } & & 12 & 428 & 505 & 429 & & \\
\hline & & & & & & & \\
\hline & & Linear Model & & Polynomial Model & & Exponential Model & \\
\hline Year & $Y_{i}$ & $Y_{i}$ & ei & $Y_{i}$ & ei & $Y_{i}$ & ei \\
\hline $2009-2010$ & 455 & 393.53 & 61.47 & 443.12 & 11.88 & 391.52 & 63.48 \\
\hline $2010-2011$ & 353 & 396.4148 & -43.4148 & 423.4668 & -70.4668 & 394.5068878 & -41.5068878 \\
\hline 2011-2012 & 411 & 399.2996 & 11.7004 & 408.3212 & 2.6788 & 397.5165624 & 13.48343758 \\
\hline $2012-2013$ & 414 & 402.1844 & 11.8156 & 397.6832 & 16.3168 & 400.5491977 & 13.45080229 \\
\hline 2013-2014 & 374 & 405.0692 & -31.0692 & 391.5528 & -17.5528 & 403.6049688 & -29.60496884 \\
\hline 2014-2015 & 371 & 407.954 & -36.954 & 389.93 & -18.93 & 406.6840523 & -35.6840523 \\
\hline 2015-2016 & 430 & 410.8388 & 19.1612 & 392.8148 & 37.1852 & 409.7866259 & 20.21337406 \\
\hline $2016-2017$ & 410 & 413.7236 & -3.7236 & 400.2072 & 9.7928 & 412.912869 & -2.912868973 \\
\hline $2017-2018$ & 441 & 416.6084 & 24.3916 & 412.1072 & 28.8928 & 416.062962 & 24.93703803 \\
\hline \multirow[t]{3}{*}{ 2018-2019 } & 435 & 419.4932 & 15.5068 & 428.5148 & 6.4852 & 419.2370869 & 15.76291312 \\
\hline & & SSE $=$ & 9487.234606 & $\mathrm{SS}=$ & 8402.053664 & SSE $=$ & 9552.455666 \\
\hline & & $\mathrm{AMA}=$ & 2.8884 & $\mathrm{AMA}=$ & 0.6282 & $\mathrm{AMA}=$ & 4.161878718 \\
\hline
\end{tabular}

Fig. 7. Differences of prediction models

According to the calculations, the best predictive model, with a residual dimension of 8402.05 and an absolute mean deviation of 0.628 , the most appropriate and closest to 0 values, is the polynomial model with the equation: $\mathrm{y}=2.2538 \mathrm{x} 2-21.907 \mathrm{x}+443.12$. Therefore, in line with the model's expectations, the most probable values for the following years are: 449, 475 and 505 students admitted to the Marketing Faculty, and we can 
reject the hypothesis that the most appropriate prediction model is the linear one.

Observationally, considering the previous analysis, i can argued that the fluctuation in the number of university admissions and the successful ones in the Baccalaureate exam is influenced to a large extent by the changes made by the e-society and the difference between generations presents the psychological consequences of the e-society. Therefore, the hypothesis that the volatility of the number of students is determined by changes in generations is confirmed.

\section{Conclusion}

To conclude what has been developed and demonstrated earlier, we can summarize the idea that today's society suffers a lot of changes due to the evolution of information and communication technology, both at the individual and at the organizational level. The new generation of individuals born with these tools at hand has a different conception of the choices they have to make, and the extent to which the technology / digital environment influences them increases as it offers them more benefits.

As can be seen, in the results of the research, the respondents have a different level of conception on the changes of the current society, and this makes them think, of course, that the influence of the new society on their decision does not necessarily have a high degree of applicability. However, the tendency to increase the number of students who choose marketing, as a field of study, shows that they take into account the social aspect, provided that this field represents one of the most affected branches of the technological aspect.

Certainly, the Internet phenomenon has a major impact on the psychic and on the method of choosing a university product, but their incidence requires a study, rather qualitative, and for a much longer period of time. However, all the changes brought about by this network, on society, and the economic, political and not only transformations, give it the right to be the most important influence factor of the last decade.
All these changes put the customer on the forefront and, practically, concentrating organizations' efforts on these developments and optimizations and on the marketing process offer both parties, and not only, longterm benefits, while at the same time bringing to the benefit of society a series of favorable results for the purpose of evolution.

The choice of the university, the place that gives them a broader perspective on their future, a vision and an opportunity for getting a job, with a special implication in the life of the new generation, is thus attained by the dynamics of the current society, and, in the present case, university marketing, remains to develop new techniques for attracting students based on its exertions.

The more organizations or universities manage to keep up with the new technologies and the information is delivered more efficiently, the more likely it is to attract and / or maintain consumers, and their decision to choose a product / service becomes more anticipative and easy to be satisfied. Although the most powerful organizations have moved into the online environment to be as close to their customers as possible, an effective marketing strategy includes various techniques or actions in the traditional environment but considering, into a large extent, changes made by the new society to the consumer.

It is extremely valuable for any type of organization, but especially for a university, to have information regarding the cognitive capabilities of its consumers, and especially their modeling factors, and also how this can be developed to obtain the desired profit from them, and the process of creating products, be continuously developed and provide benefits to society.

Summarizing the aforementioned aspects, we can see that the key factor of the new society is the behavior of individuals or their modification, and its control offers an advantage to any organization, even universities that are responsible for the behavior of future generations. 


\section{References}

[1] I. Alnfrah and S. Mouselli, "The Knowledge Society Vis-à-vis the Knowledge Economy and Their Potential Development Impacts in Russia," Journal of the Knowledge Economy, vol. 10, no. 1, pp. 205-220, 2019.

[2] O. Serrat, "Understanding and Developing Emotional Intelligence," Knowledge Solutions, pp. 329-339, 23 May 2017.

[3] J. D. Hess and A. C. Bacigalupo, "Enhancing decisions and decisionmaking processes through the application of emotional intelligence skills," Management Decision, pp. 710-721, 31 May 2011.

[4] J. D. Mayer, D. R. Caruso and P. Salovey, "The Ability Model of Emotional Intelligence: Principles and Updates," Emotion Review, vol. 8, no. 4, October 2016.

[5] M. Newman, "Emotional Capital Report," RocheMartin, Melbourne, 2010.

[6] N. Stehr and M. Adolf, Knowledge is a knowledge power?, New York: Routldge Taylor and Francis Group, 2017.

[7] K. C. Laudon and C. G. Traver, ECommerce business. technology. society, 10th ed., New York: Pearson, 2014.

[8] J. Clement, "Statista," 2019. [Online]. Available:

https://www.statista.com/statistics/26481 0/number-of-monthly-active-facebookusers-worldwide/. [Accessed February 2019].

[9] M. Ursăcescu, Economia informației și a cunoștințelor, Bucharest: Editura Universitară, 2009.

[10] P. Rajasekhar, C. Veena and K. Srujan, "Gender differences in internet preferences and usage pattern among medical students," National Journal of Physiology, Pharmacy and Pharmacology, vol. 8, no. 5, pp. 683-686, 2018.

[11] M. Stoica, "Premise ale trecerii la societatea informațională," Informatică Economică, pp. 42-46, 2000.

[12] M. Andreas and T. Luis, eDemocracy \& eGovernment - Stages of a Democratic Knowledge Society, Fribourg: Springer, 2012.

[13] M. Lucas, J. Ribeiro and A. Moreira, "Bypassing school Disenchantment: Strategies to Promote School Attainment," in Information Systems, E-learning, and Knowledge Management Research: 4th World Summit on the Knowledge Society, Mykonos, 2013.

[14] T. Nicholas and M. Wright, "Generational differences: understanding and exploring generation Z," in Southwest Academy of Management Proceedings , Huston, 2018.

[15] J. Desjardins, "Meet Generation Z: The Newest Member to the Workforce," Visual Capitalist, 14 February 2019. [Online]. Available: https://www.visualcapitalist.com/meetgeneration-z-the-newest-member-to-theworkforce/?fbclid=IwAR0E8oGfVDJpZ EaYHEDEl7be_Azsv0uos8qhH85vMlA5 rS9-K_afFqOcjck. [Accessed 25 February 2019].

[16] A. Zaiț, Marketingul Serviciilor, Iași: Sedcom Libris, 2004.

[17] Edu.ro, "Bacalaureat 2017," 15 February 2017. [Online]. Available: https://www.edu.ro/sites/default/files/170 710\%20BAC\%20DOSAR\%20v2.pdf. [Accessed March 2019].

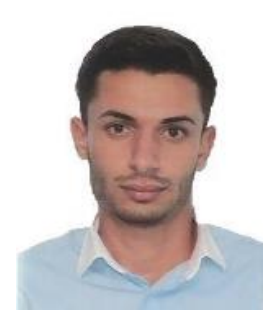

Ion-Dănuț LIXANDRU has graduated The Faculty of Marketing from The Bucharest University of Economic Studies in 2016. He has a master's degree in Strategic Marketing (2018) and a PhD student in Marketing starting from 2018 in the field of Strategies and Tactics in Higher Education Marketing. His current research focuses on decision-making process for choosing university products, he wants to develop a model for determining purchase intention based on the influence of exogenous and endogenous factors in Higher Education. 